\title{
Risk factors of Non-Communicable Diseases in India: A Systematic Review
}

\author{
Dhruv Agarwal ${ }^{1}$, Mukesh Shukla ${ }^{2}$, Nirpal Kaur Shukla ${ }^{1}$, Ram Shukla $^{3}$, Harinder Pal Kaur Sidhu ${ }^{4}$ \\ 1Post-graduate Resident, Hind Institute of Medical Sciences, Safedabad, Barabanki, Uttar Pradesh, India. \\ ${ }^{2}$ Assistant Professor, Hind Institute of Medical Sciences, Ataria, Sitapur, Lucknow, Uttar Pradesh, India. \\ 3Faculty, Sherwood College of Management, Lucknow, Uttar Pradesh, India. \\ ${ }^{4}$ Senior Medical Officer, Fortis Heart Institute and Multispeciality Hospital, Mohali, Punjab, India.
}

\section{ABSTRACT}

Background: India is experiencing a rapid health transition with a rising burden of NCDs (Non-Communicable Diseases) causing significant morbidity and mortality, both in rural and urban population, with considerable loss in potentially productive years (age 35-64 years) of life. So, a systematic review of published studies was done to understand the pattern of NCDs risk factors in India.

Methods: The Medline and Cochrane library database were searched. Any prospective or retrospective study, both quantitative and qualitative published since 2008 were included. Data were extracted independently and quality assessment was conducted on standard risk factor definition (WHO STEPs strategy), epidemiological estimates, study design, study population characteristics and assessment methods. Of the 132 published articles screened, 14 studies met the inclusion criteria and were included in the review.

Results: Prevalence of overweight and obesity ranged from 2.4 to $33.1 \%$ and 2.2 to $77.5 \%$ respectively. Tobacco chewing, smoking and alcohol consumption were found to range widely between $12.15-54.9 \%, 4.1-81.5 \%$ and 7.9-38.93\% respectively. Diabetes known to be one of the

\section{INTRODUCTION}

Globally, the total number of deaths reported in 2012 were about 56 million, and $68 \%$ of them (38 million) were attributed to NCDs. Cardio-vascular diseases contribute about $47.9 \%$ of all NCD's mortality, followed by cancer (21\%), Chronic respiratory diseases (11.72\%), Digestive diseases (6.1\%), Diabetes (3.5\%) and rest of the NCDs $(9.78 \%) .{ }^{1}$ The adoption of a common risk-factor approach to NCDs prevention is a major development in the thinking behind an integrated health policy. A "risk factor" refers to any attribute, characteristics or exposure that is significantly associated with the development of a disease. ${ }^{2}$ Sociodemographic transition has brought major changes in the health behaviours and health profile of people both in developed and developing nations. Changes in the world economy are reflected as changing dietary patterns and increased consumption of energy-rich diets that are high in fat, particularly saturated fat, and low in unrefined carbohydrates. Because of these changes in dietary patterns and associated lifestyle changes; non communicable diseases (NCD) -like Diabetes mellitus (DM), cardiovascular disease (CVD), Hypertension (HTN), Stroke, and important predictive risk factor, ranged between 3.7-26.72\% while high BP estimates varied from 5.7 to $48.3 \%$.

Conclusions: Risk factors of non-communicable diseases are quite prevalent in Indian population. Risk factor control along with early diagnosis and treatment is highly warranted to get a grasp over NCDs.

Keywords: NCDs, Risk factors.

\section{${ }^{*}$ Correspondence to:}

\section{Dr. Mukesh Shukla}

96-HA Vihar Panigaon, Indiranagar, Lucknow, Uttar Pradesh, India.

Article History:

Received: 10-08-2016, Revised: 13-08-2016, Accepted: 20-08-2016

\begin{tabular}{|l|c|}
\hline \multicolumn{2}{|c|}{ Access this article online } \\
\hline $\begin{array}{l}\text { Website: } \\
\text { www.ijmrp.com }\end{array}$ & Quick Response code \\
\hline DOI: & \\
10.21276/ijmrp.2016.2.5.002 & \\
\hline
\end{tabular}

some types of cancer are becoming increasingly significant causes of disability as well as premature death. One of the effects of this economic transition is reflected as epidemiological transition shift in the disease spectrum from communicable to noncommunicable diseases. ${ }^{3}$ India like other developing countries is passing through an epidemiological health transition affecting both urban and rural areas. Increasing prevalence of noncommunicable disease risk factors, especially in rural areas, has important public health implications, as two thirds of India's one billion population still lives in rural areas. ${ }^{4}$ Further, rural populations have limited access to health care and can least afford to pay for the high treatment costs for chronic diseases. ${ }^{5}$ World Health Organization (WHO, 2002) estimates that positive changes in health behaviours- not smoking, eating a healthy diet, maintaining normal weight, and being physically active, can reduce the risk of coronary heart disease, stroke, and diabetes by about three quarters and cancers by one third. ${ }^{6}$ Beyond the appropriate medical treatment for those already affected, the public health approach of primary prevention is considered to be 
the most cost-effective, affordable and sustainable course of action to cope with the chronic disease epidemic worldwide. Policies and programmes focusing on reducing the burden of these common risk factors for NCD are likely to make a substantial impact on mitigating of mortality and morbidity due to NCDs. ${ }^{7}$

World Health Organization (WHO) has developed the STEPs approach to conduct NCD risk- factor-surveillance to monitor these risk factors. ${ }^{8}$ Assessing the socio-demographic patterns of NCDs risk factors across rural India is important not only for predicting the future trends but also for developing relevant preventive policies. The aim of the present study is to systematically review the risk factors of NCDs in India.

\section{METHODS}

We systematically searched online databases for reports published since 2008. Studies were screened against inclusion criteria; two authors then independently extracted data. Data available for various risk factors were overviewed in each study for various study population, which were almost similar in respect to age and sex.

\section{Literature search}

We searched the Medline (Pubmed) and Cochrane library database until 2008 using combinations of the following text and MeSH terms: "Non-communicable disease","Chronic diseases", "Risk factors" and "India" for all included years. No limits were applied on the basis of language, population or time period.

\section{Study selection}

The study selections were based on original articles about various risk factors of NCDs in India. Both title and abstract review of all the selected articles, with the following inclusion and exclusion criteria was done so as to identify the relevant studies.

\section{Inclusion criteria}

- Research articles on Non communicable disease and risk factors.

- Studies conducted within the geographical boundaries of India.

\section{Exclusion criteria}

- Case-reports, review articles and conference abstracts.

\section{Study selection and data extraction}

Two reviewers independently appraised the list of references and assessed the studies for their eligibility. Any disagreements were resolved by consensus. Data were extracted on operational definitions and assessment of risk factors, epidemiological estimates, study design, study population characteristics and study time frame. We also emphasised and discussed data on the methodological quality of the included studies.

\section{Analysis}

As the present review aimed to elaborate risk factors of NCDs in India in different populations, demographic area and at dissimilar frame of time, a wide heterogeneity in the results was expected. Apart from that, the demographic area, timing of obtaining samples, laboratory methods, and range of risk factors estimated were more likely to be dissimilar over time. That's why, pooled estimates for any demographic characteristic or etiologic agents were not estimated and only a descriptive analysis of the studies has been provided.

\section{RESULTS}

Various electronic databases were searched for studies and after screening of title, abstract and full articles 14 research studies were found to meet the inclusion criteria. Of them,

4 were multicentre studies.

\section{Multicenteric studies}

In a multicenteric study, conducted by Thankappan et al., reported prevalence rate of obesity to be much high (33.9\%) among all the risk factors with physical inactivity $(6.9 \%)$ as the lowest. Prevalence of high BP, overweight, DM, alcohol consumption were $28.8 \%, 24.9 \%, 14.8 \%$ \& $11.1 \%$ respectively. ${ }^{10}$ Another multicenteric study conducted by Kinara et al., revealed prevalence of cigarette smoking to be high $(29 \%)$ as compared with alcohol consumption (18\%). Bhagyalaxmi et al., in their study reported lack of physical inactivity to be high in urban areas $(38.9 \%)$ in comparison with the rural population $(32.2 \%)$ while prevalence of cigarette smoking to be low in urban areas $(6.6 \%)$ and high in rural areas (12.2\%). Also prevalence of high BP was high in urban areas (29.1\%) as compared to rural areas (15.4\%), while obesity and overweight was relatively higher in urban areas $(38.1 \%$ \& $30.2 \%)$ than rural areas $(14.4 \%$ \& $11.9 \%)$, but prevalence of tobacco chewing in rural areas was high (32.9\%) in comparison with urban areas (14.2\%). ${ }^{13}$ Sogarwala et al., in their multicenteric study found prevalence of cigarette smoking was higher $(31.5 \%)$ in comparison with alcohol consumption (7.9\%). ${ }^{15}$ (Table 1)

\section{Prevalence of risk factors}

Tobacco chewing, smoking and alcohol consumption were found to range from $12.15-54.9 \%, 4.1-81.5 \%$ and $7.9-38.93 \%$ respectively. Prevalence of overweight and obesity varied between $2.4-33.1 \%$ and $2.2-77.5 \%$ respectively while lack of physical activity estimates varied from $6.9-86.0 \%$. Diabetes as a risk factor range from $3.7-26.72 \%$ respectively while high $\mathrm{BP}$ estimates varied between $5.7-48.3 \%$. (Table 2)

\section{DISCUSSION}

The aim of this study was to systematically review the literature on risk factors of NCDs in India. Fourteen original articles, consisting of four multicenteric studies that met the inclusion criteria were considered. The prevalence of various risk factors of NCDs ranged widely. Like the studies in different part of the world a difference was observed in the prevalence of risk factors in rural and urban population. ${ }^{23-26}$ Similarly in one of the multicenteric study reviewed, a wide range of difference was observed with respect to tobacco chewing, lack of physical activity, high BP, obesity/overweight. Manouk Bos opined that increasing urbanisation and life expectancy with a difference in the life style changes might be the reason for such difference between rural and urban population. ${ }^{27}$ Low intake of fruits and vegetables are found to be associated with NCD's. ${ }^{28,29}$ One of the reviewed study reported inadequate intake of fruit and vegetable in about sixty eight per cent of the population, which emphasized a need for inter-sectoral cooperation and combined efforts among different stake holders in order to increase not only the production but also the awareness among population towards best dietary pattern adaption in their routine life.

Lack of physical activity is one of the important factors for predetermining NCD's. ${ }^{30}$ In the present review work, lack of 
Dhruv Agarwal et al. Risk factors of Non-Communicable Diseases in India

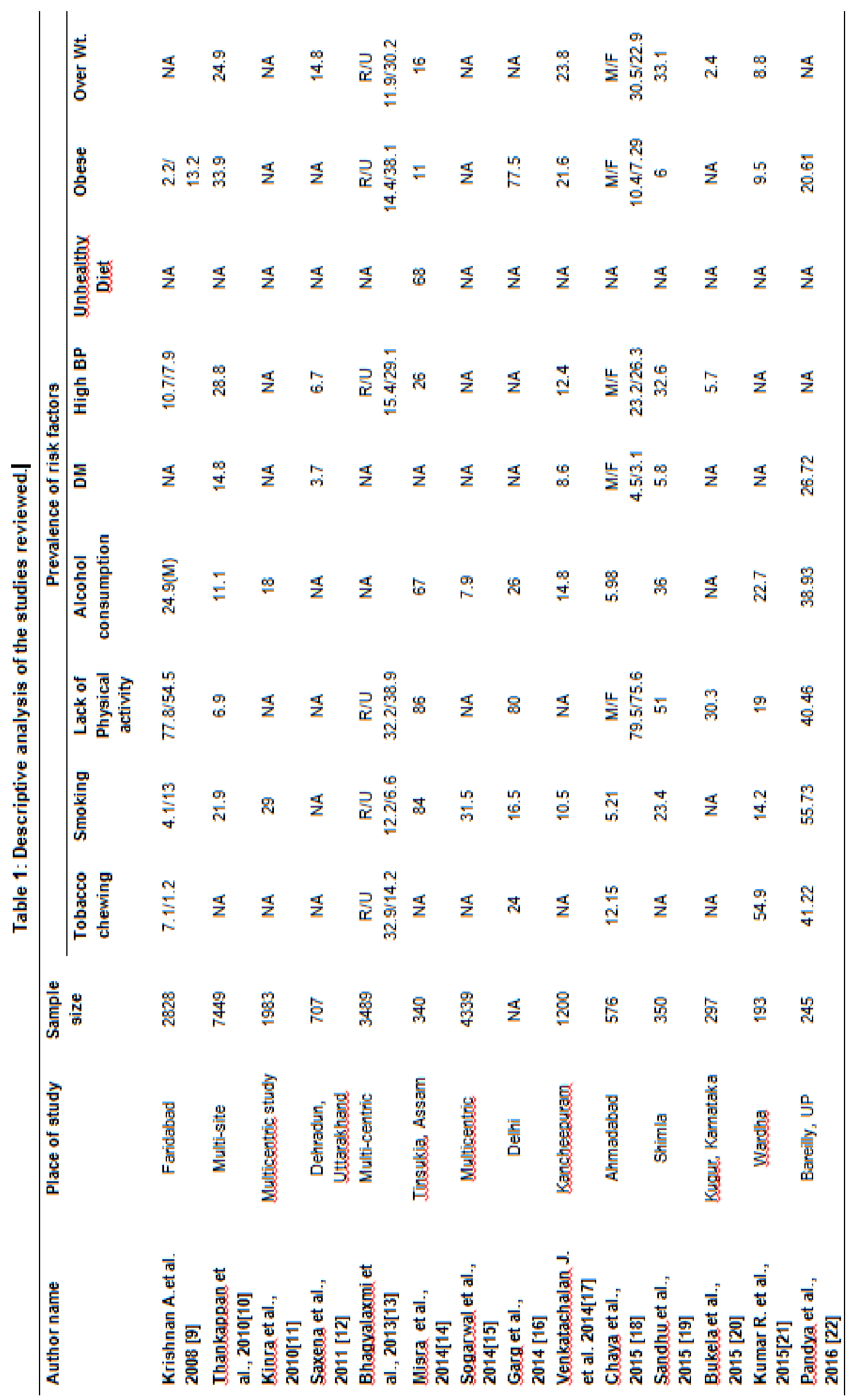


Dhruv Agarwal et al. Risk factors of Non-Communicable Diseases in India

Table 2: Prevalence of various risk factors based on the systemic review of various Indian studies

\begin{tabular}{|c|c|}
\hline Risk Factors & Prevalence range (\%) \\
\hline Tobacco Chewing & $12.15-54.9$ \\
\hline Smoking & $4.1-81.5$ \\
\hline Lack of Physical Activity & $6.9-86$ \\
\hline Alcohol Consumption & $7.9-38.93$ \\
\hline Diabetes Mellitus & $3.7-26.72$ \\
\hline High Blood Pressure & $5.7-48.3$ \\
\hline Obesity & $2.2-77.5$ \\
\hline Over weight & $2.4-33.1$ \\
\hline Inadequate intake of fruits and vegetables & $68^{*}$ \\
\hline
\end{tabular}

physical activity varies from 6.9 to 86 per cent. The estimates are quite similar to those reported at global level. ${ }^{31}$

Smoking and tobacco is considered as number one enemy of public health. The estimates were similar to the recent study conducted in the neighbouring country- Bangladesh, ${ }^{32}$ and also as per Global Adult Tobacco Survey (GATS). ${ }^{33}$

Obesity is expanding its domain in both the developed and developing countries. The review of the Indian study reported the prevalence of obesity and overweight vary in between 2.4-33.1\% \& 2.2- $77.5 \%$ respectively with central obesity having more preponderance. Same pattern has been also observed in the studies of other countries of South East Asian Region. Hypertension is the most important risk factors for cardio-vascular diseases found to having prevalence range of $5.7-48.3 \%$ in the present review work. Similar findings are also reported in other studies. ${ }^{32,34}$

\section{LIMITATIONS}

The reviews have some limitations; limited number of studies over past decades is available in context to risk factors of NCD's in India. In few review studies there was a mere difference in assessment criteria for the NCD's which might have had let differences in prevalence of NCD's risk factors. Apart from that, the review studies were conducted from 2008 to 2016. Therefore in order to make an accurate estimate of prevalence of various risk factors of NCD's, it would be best to compare studies conducted over same period of time; however there was limited number of studies. Despite these limitations the current review provides inferential results about various risk factors of NCD's.

\section{CONCLUSIONS}

Non communicable diseases are important and common health problems in India. Use of tobacco, low level of physical activity, obesity including overweight, diabetes, lack of intake of fruit and vegetables are quite common in Indian population. Therefore there is need of population-based strategy through comprehensive health services so as to reduce the risk of NCDs. Apart from that early diagnosis with proper treatment facilities must be provided to already existing population having NCDs. All the stake holders along with community participation should be actively involved for the prevention of risk factors.

\section{REFERENCES}

1. WHO (2015), Global status report on non-communicable diseases 2012. Available from: http:/l www.who.int/ nmh/publications/ ncd-status-report-2014/ en/

[Last accessed on June 25, 2016]

2. Park K. Park's Textbook of Preventive and Social Medicine. 23rd. Jabalpur, India: M/S Banarsidas Bhanot Publishers; 2007.p.38.

3. Mohan V, Deepa R. Risk factors for coronary artery disease in Indians. J Assoc Physicians India 2004; 52:95-7

4. Sivaramakrishnan KC, Kundu A, Singh BN. Handbook of urbanisation in India. Oxford University Press, 2007.

5. Alleyne G, Binagwaho A, Haines A, Jahan S, Nugent R, 2. Rojhani $A$, et al. embedding non-communicable diseases in the post-2015 development agenda. Lancet 2013; 381: 566-74

6 . Beaglehole R, Magnus $P$. The search for new risk factors for coronary heart disease: Occupational therapy for epidemiologists. Int J Epidemiology 2002; 31:1117-22.

7. Epping-Jordan JE, Galea G, Tukuitonga C, Beaglehole R. Preventing chronic diseases taking stepwise action. Lancet 2005; 366:1667-71.

8. WHO STEPs Manual. Available from :http:// www1.paho.org/ $\mathrm{hq} /$ dmdocuments/2009/ STEPSmanual.pdf [Last accessed on July 23, 2016]

9. A. Krishnan, Shah B, Lal Vivek, Shukla D. K., Paul Eldho, Kapoor S. K., Prevalence of Risk Factors for Non-Communicable Disease in a Rural Area of Faridabad District of Haryana. Indian Journal of Public Health 2008 ;52(3):117-24

10. Thankappan KR, Shah Bela, Mathur Prashant, Sarna PS, Srinivas G, Mini GK, Daivadanam Meena, Soman Biju, Vasan Ramachandran S. Risk factor profile for chronic noncommunicable diseases: Results of a community-based study in Kerala, India, Indian. Journal of Medical Research. 2009:53-63.

11. Kinra Sanjay, Bowen Liza J, Lyngdoh Tanica, Prabhakaran Dorairaj, Reddy KS, Ramakrishnan Lakshmy. Socio-demographic patterning of non-communicable disease Risk factors in rural India: a cross sectional study. BMJ 2010; 341:c4974.

12. Saxena V, Kandpal S D, Goel D, Bansal S. Prevalence of Risk factors of Non-communicable Diseases in rural population of India. J Epidemiol Community Health 2011;65:A413 doi:10.1136/jech.2011.1429760.16. 
13. Bhagyalaxmi Aroor, Trivedi Atul, Jain Shikha, Prevalence of Risk Factors of Non-communicable Diseases in a District of Gujarat, India. J HEALTH POPUL NUTR 2013; 31(1):78-85.

14. Misra Palash Jyoti, Mini G.K., Thankappan K. R., Risk factor profile for non-communicable diseases among Mishing tribes in Assam, India: Results from a WHO STEPs survey. Indian J Med Res. 2014 Sep; 140(3): 370-378.

15. Sogarwal R., Bachani D., Kumar Bharath, Gupta Sanjay, Risk Factors of Non-Communicable Diseases among Higher Secondary School Students in Selected Districts of India. American Journal of Public Health Research 2014; 2(1) : 16-20.

16. Garg Ankur, Anand Tanu, Sharma Urvi, Kishore Jugal, Chakraborty Mantosh, Ray Prakash Chandra, Prevalence of Risk Factors for Chronic Non-communicable Diseases Using WHO Steps Approach in an Adult Population in Delhi, Family Med Prim Care. 2014; 3(2): 112-118. Doi: 10.4103/2249-4863.13761

17. Venkatachalam J, Purty Anil J, Singh Zile, Abraham SB, Narayanan S, Sathya GR, Bhumika Natesan, Prevalence of Non Communicable Diseases (NCDs) in a Rural Population of South India., International Journal of Contemporary Medicine 2014;2(1):32-38

18. Chhaya Jain, Devalia Jayna, Kedia Geeta, Prevalence of Risk Factors and its Association with Non-Communicable Disease among the Faculty Members of Teaching Institute of Ahmadabad City, Gujarat: A Cross-Sectional Study., International Journal of Scientific Study 2015;3(8): 159-162.

19. Sandhu S, Chauhan R, Mazta S R. Prevalence of Risk Factors for Non-communicable Diseases in Working Population. MAMC J Med Sci 2015; 1(2): 101-104

20. Bukelo Maria Frances, Deepthi Kiran, Ramakrishna Goud B, Bukelo Mario Joseph, Kiran Pretesh Rohan, Kulkarni Vaman, Risk Factor for Non-communicable diseases among rural Adolescents: A School based cross-sectional study, Asian Journal of Pharmaceutical and Clinical Research. 2015;8(2);123-39.

21. Kumar Rakesh, Anthropometric and Behavioral Risk Factor for Non-Communicable: Diseases: A Cluster Survey from Rural Wardha., Indian Journal of Public Health.2015;59(1);234-38.

22. Pandya Rajivkumar Bipinchandra, Sharma Sanjay Kumar, Siddiqui Sadiq Wadood, Gangwar Sashank, Study of Patterns of Non-Communicable Diseases at a Tertiary Care Teaching Hospital, Int J Med Res Prof.2016;2(1); 111-13.

23. Tazi MA, Abir-Khali S, Chaouki N, Chergaoui S, lahmouz F, Srairi JE, Mahjour J; Prevalence of the main cardio-vascular risk factors in Morroco: results of a National Survey, 2000. J Hypertens 2003 May, 21(5):897-903.

24. Herman WH, Ali MA, Aubert RE, Engelgau MM, Kenny SJ, Gunter EW, Malarcher AM, Brechner RJ, Wetterhall SF, DeStefano F: Diabetes mellitus in Egypt: risk factors and prevalence. Diabet Med 1995 Dec, 12(12):1126-1131.
25. Kadiki OA, Roaeid RB: Prevalence of diabetes mellitus and impaired glucose tolerance in Benghazi Libya. Diabetes Metab 2001 Dec, 27(6):647-654.

26. Elasmi M, Feki M, Sanhaji H, Jemaa R, Haj Taeib S, Omar S, Mebazaa A, El Ati J, Hsairi M, Kaabachi N: Prevalence of conventional cardiovascular risk factors in the Great Tunis population. Rev Epidemiol Sante Publique 2010;36(3):204-208.

27. Bos and Agyemang: Prevalence and complications of diabetes mellitus in Northern Africa, a systematic review. BMC Public Health 2013 13:387.

28. National health archive UK. The School Fruit and Vegetable Scheme, 5 A Day programme. Available from: http://www.dh.gov.uk/PolicyAndGuidance/HealthSocialCareTopics /FiveADay/fs/en. [Last accessed on Jan 15, 2016].

29. Department of Health. Nutritional aspects of cardiovascular disease. Report on Health and Social Subjects. London: HMSO, 1994. p. 32.

30. Chakravarthy MV, Joyner MJ, Booth FW. An obligation for primary care physicians to prescribe physical activity to sedentary patients to reduce the risk of chronic health conditions. Mayo Clin Proc 2002; 77:165-73.

31. Mathers CD, Loncar D. Projection of global mortality and burden of disease from 2002 to 2030. PLoS Med 2006;3:e442.

32. Zaman MM, Rahman M, Rahman M, Bhuiyan MR, Karim M, Chowdhury MJ. Prevalence of risk factors for non-communicable diseases in Bangladesh: Results from STEPS survey 2010. Indian J Public Health 2016;60:17-25.

33. World Health Organization. Health Profile of Bangladesh. WHO Bangladesh, 2003. Available from: http://www. whoban.org/ country_health_profile.html. [Last accessed on 2010 Oct 22].

34. Nawi Ng, Hans Stenlund, Ruth Bonita, Mohammed Hakim, Stig Wall, \& Lars Weinehall.: Preventable risk factors for noncommunicable diseases in rural Indonesia: prevalence study using WHO STEPS approach. Bulletin of World Health Organization; April 2006, 84(305-313).

\section{Source of Support: Nil. Conflict of Interest: None Declared.}

Copyright: (c) the author(s) and publisher. IJMRP is an official publication of Ibn Sina Academy of Medieval Medicine \& Sciences, registered in 2001 under Indian Trusts Act, 1882.

This is an open access article distributed under the terms of the Creative Commons Attribution Non-commercial License, which permits unrestricted non-commercial use, distribution, and reproduction in any medium, provided the original work is properly cited.

Cite this article as: Dhruv Agarwal, Mukesh Shukla, Nirpal Kaur Shukla, Ram Shukla, Harinder Pal Kaur Sidhu. Risk factors of Non-Communicable Diseases in India: A Systematic Review. Int J Med Res Prof. 2016; 2(5):6-10. 